\title{
RANCANG BANGUN SISTEM INFORMASI RUMAH KOST DAN KONTRAKAN TELUK KUANTAN
}

\author{
Elgamar Syam \\ Program Studi Teknik Informatika, Fakultas Teknik \\ Universitas Islam Kuantan Singingi (UNIKS) \\ Jl. Gatot Subroto Km. 7 Jake, Teluk Kuantan \\ E-mail : elgamar@uniks.ac.id
}

\begin{abstract}
Abstrak
Pemanfaatan Teknologi dan Informasi dalam pengembangan suatu bisnis sangat diperlukan pada zaman milenial sekarang ini, dengan adanya sentuhan teknologi maka bisnis atau usaha dapat bertahan dan berkembang menjadi lebih baik. Sementara mereka yang tetap bertahan menggunakan cara tradisional, maka akan tergerus oleh kemajuan teknologi itu sendiri. Salah satu contoh pengembangan bisnis digital adalah pemanfaatan sistem informasi digital dalam promosi rumah kost dan kontrakan yang ada di wilayah Kabupaten Kuantan Singingi (Teluk Kuantan) Riau. Sehingga dengan adanya sistem ini para pemilik rumah kost dan kontrakan dapat mempromosikan huniannya melalui sistem informasi yang dibangun. Sistem ini menawarkan kemudahan bagi sipencari rumah kost dan kontrakan untuk melakukan penyewaan. Begitu juga dengan pemilik kost, maka dengan mudah menawarkan rumah kost dan kontrakan yang dimiliki agar dapat disewa dan dihuni oleh sipencari rumah kost, tentunya pembuat sistem juga akan mendapatkan keuntungan dari setiap transaksi yang dilakukan. Sistem informasi ini, memberikan gambaran jelas kepada si pencari rumah kost dan kontrakan dalam memilih hunian yang mereka lihat di halaman sistem informasi ini sesuai dengan selera dan kebutuhan mereka masing-masing.
\end{abstract}

Kata kunci : Sistem Informasi, Kos Online, Bisnis Digital

\section{PENDAHULUAN}

Salah satu permasalahan yang dirasakan oleh pendatang, mahasiswa atau pelajar yang berada di daerah Kabupaten Kuantan Singingi khususnya Kota Teluk Kuantan - Riau adalah sulitnya mencari tempat tinggal yang nyaman dan aman sesuai selera masing-masing. Hal ini disebabkan keterbatasan informasi yang diperoleh dari masyarakat secara langsung, apalagi mengharuskan si penyewa mencari hunian yang dekat dengan tempat kerja, sekolah atau kampus tempat mereka melaksanakan aktifitas sehari-hari. Sangat banyak sekali permasalahan yang dirasakan saat harus mencari sendiri tempat tinggal yang sesuai dengan selera, baik dilihat dari sisi waktu yang dihabiskan, tenaga, pikiran dan materi yang terkuras mencari hunian yang akan ditempati.

Pemanfaatan sistem dan teknolgi informasi secara digital dirasakan mampu memberikan solusi terhadap permasalahan tersebut. Teknologi dan informasi yang dirancang dapat memberikan gambaran kepada masyarakat secara umum, dan kepada si pencari tempat tinggal khususnya. Sistem yang dirancang berbasis website dengan menggunakan fasilitas internet dalam proses pencarian dan pemilihan hunian yang tepat, sehingga dengan mudah si pencari hunian melihat menggunakan perangkat mobile atau komputer yang dimiliki. Sistem ini menawarkan informasi yang up to date, detil dan lengkap baik informasi harga, fasilitas, lokasi, gambar dalam hunia dan luar hunian serta lingkungan yang berada disekitarnya. 


\section{TINJAUAN PUSTAKA}

\subsection{Pengertian Sistem dan Informasi}

Menurut Davis dalam Jogiyanto (2005), "sistem dapat berupa abstrak atau fisik, system yang abstrak adalah susunan yang teratur dari gagasan-gagasan tentang tuhan, manusia dan sebagainya, sedangkan system yang bersifat fisik adalah serangkaian unsur yang bekerja sama untuk mencapai tujuan".

Menurut Robert A. Leitch dan K. Roscoe Davis dalam Dadi Rosadi dan Feby Oktarista Andriawan (2016), sistem informasi adalah suatu organisasi yang mempertemukan kebutuhan pengolahan transaksi harian, mendukung operasi, bersifat manajerial dan kegiatan strategi dari suatu organisasi dan menyediakan pihak luar tertentu dengan laporan-laporan yang diperlukan" (Analisis dan Desain Sistem Informasi : Pendekatan terstruktur teori dan praktik aplikasi, $2005: 11)$.

Berdasarkan pengertian tersebut, dapat kita simpulkan bahwa sistem merupakan satu kesatuan yang tidak dapat dipisahkan satu sama lainnya dalam mencapai tujuan tertentu. Sedangkan informasi memberikan gambaran umum ataupun secara jelas dan detil kepada pengguna, sehingga mendapatkan manfaat dari sistem dan informasi tersebut.

\subsection{Kajian Terdahulu}

\begin{tabular}{|c|c|c|}
\hline Judul Penelitian & Penulis & Hasil \\
\hline $\begin{array}{l}\text { Sistem Informasi Sewa } \\
\text { Rumah Kost Dan Rumah } \\
\text { Kontrakan Berbasis Web Di } \\
\text { Surakarta. } \\
\text { (Jurnal Ilmiah Go Infotech, } \\
\text { Volume } 22 \text { No. 1, Juni 2016) }\end{array}$ & $\begin{array}{l}\text { Didit Gunawan, Robby } \\
\text { Racmatullah }\end{array}$ & $\begin{array}{l}\text { Sistem Informasi Sewa Rumah } \\
\text { kost dan Kontrakan di Surakarta } \\
\text { berbasis web iniMembantu dalam } \\
\text { memberikan informasi kepada } \\
\text { konsumen tentang kamar yang } \\
\text { sudah terisi dan memungkinkan } \\
\text { pelanggan mendapatkan detail } \\
\text { informasi tentang kos yang di cari }\end{array}$ \\
\hline $\begin{array}{l}\text { Aplikasi Sistem Informasi } \\
\text { Pencarian Tempat Kos Di } \\
\text { Kota Bandung Berbasis } \\
\text { Android. } \\
\text { (Jurnal Computech \& Bisnis, } \\
\text { Volume 10, No. 1, Juni 2016, } \\
\text { 50-58, ISSN 2442-4923) }\end{array}$ & $\begin{array}{l}\text { Dadi Rosadi, Feby } \\
\text { Oktarista Andriawan }\end{array}$ & $\begin{array}{l}\text { Pencarian informasi kos menjadi } \\
\text { lebih mudah dan efisien, aplikasi } \\
\text { mudah digunakan, dan proses } \\
\text { filter yang efisien membuat } \\
\text { pengguna tidak perlu masuk ke } \\
\text { search engine. }\end{array}$ \\
\hline $\begin{array}{l}\text { Sistem Pencarian Dan } \\
\text { Pemesanan Rumah Kos } \\
\text { Menggunakan Sistem } \\
\text { Informasi Geografi (SIG). } \\
\text { (Jurnal Script Vol. 1 No. } 2 \\
\text { Januari 2014 Issn:2338-6304) }\end{array}$ & $\begin{array}{l}\text { Harri Singgih Pratikto, } \\
\text { Suraya, Edhy Sutanta }\end{array}$ & $\begin{array}{l}\text { Menyajikan informasi detail, } \\
\text { memberikan efisiensi waktu, serta } \\
\text { memudahkan pemilik dan pencari } \\
\text { rumah kos untuk melakukan } \\
\text { pencarian. }\end{array}$ \\
\hline
\end{tabular}




\section{METODE PENELITIAN}

Sebagai penunjang penulisi dalam melakukan penelitian, maka penulis melakukan penelitian ini menggunakan metode penelitian terapan, dimana penelitian diarahkan untuk mendapatkan informasi yang dapat memecahkan permasalahan, dengan tujuan mampu menerapkan, menguji dan melakukan evaluasi permasalahan yang dihadapi.

\subsection{Teknik Pengumpulan Data}

1. Observasi, merupakan suatu cara yang ditempuh dengan melakukan pengamatan secara langsung.

2. Wawancara, merupakan sebuah kegiatan tanya jawab kepada orang yang memiliki kapasitas terkait dalam penelitian.

3. Studi Pustaka, merupakan teknik yang dilakukan untuk mendapatkan rujukan dari buku, jurnal, dokumen yang terkait dengan penelitian.

4. Dokumentasi, merupakan teknik pengumpulan data dengan menghimpun hasil dokumentasi seperti gambar maupun tulisan dan kemudian dianalisa.

\subsection{Perancangan Program}

Perancangan dilakukan untuk memudahkan dalam pembangunan aplikasi, sehingga sesuai dengan apa yang telah dirancang meliputi peracangan desain secara global.

\subsection{Pengkodean}

Proses coding merupakan tahapan yang dilakukan setelah perancangan desain secara global dilakukan, sehingga sesuai dengan perancangan program, dan sistem ini dibangun dengan pengkodingan menggunakan bahasa pemrograman PHP.

\subsection{Pengujian}

Pengujian merupakan salah satu tahapan dalam pembangunan sistem informasi ini, sehingga ketika sistem dijalankan tidak terdapat kendala dan permasalahan.

\subsection{Implementasi}

Proses implementasi dilakukan setelah proses pengujian dianggap layak untuk di publikasikan kepada pengguna.

\subsection{Evaluasi}

Proses evaluasi dilakukan apabila terdapat kelemahan pada sistem informasi yang dibangun.

\section{HASIL DAN PEMBAHASAN}

Pembangun sistem informasi ini dibutuhkan pembahasan untuk menguraikan program dan analisa dari hasil program yang telah dibuat, sehingga terlihat jelas apakah sistem yang telah dibuat mampu memenuhi kebutuhan pengguna. Pengujian awalnya dilakukan pada browser dengan mode offline (localhost), setelah berjalan dengan baik barulah kemudian dilakukan uji coba dengan mode online (via hosting dan domain).

Berdasarkan perancangan dan implementasi sistem, maka sistem informasi ini menggunakan 2 hak akses yakni administrator dalam hal pengelolaan dan user dalam hal penggunaan.

\section{Administrator}

Administrator adalah orang yang bertugas atau ditugaskan untuk mengelola, memeriksa dan memasukkan data-data yang dibutuhkan dan kemudian menampilkan kedalam sistem informasi sewa rumah kost dan kontrakan. Pada sistem ini, administrator mengelola dan mengontrol secara penuh transaksi yang dilakukan user atau member.

\section{User or Member}

User atau member adalah orang orang menggunakan fasilitas dari sistem informasi sewa rumah kost dan kontrakan berbasis web untuk membantu memenuhi kebutuhan mencari informasi rumah kost dan kontrakan yang ada di Teluk Kuantan. 
Sistem ini memiliki fasilitas upload gambar dan rincian rumah kost dan kontrakan yang terdiri dari fasilitas yang diberikan, harga sewa, lokasi dan kontak pemilik rumah kost dan kontrakan.

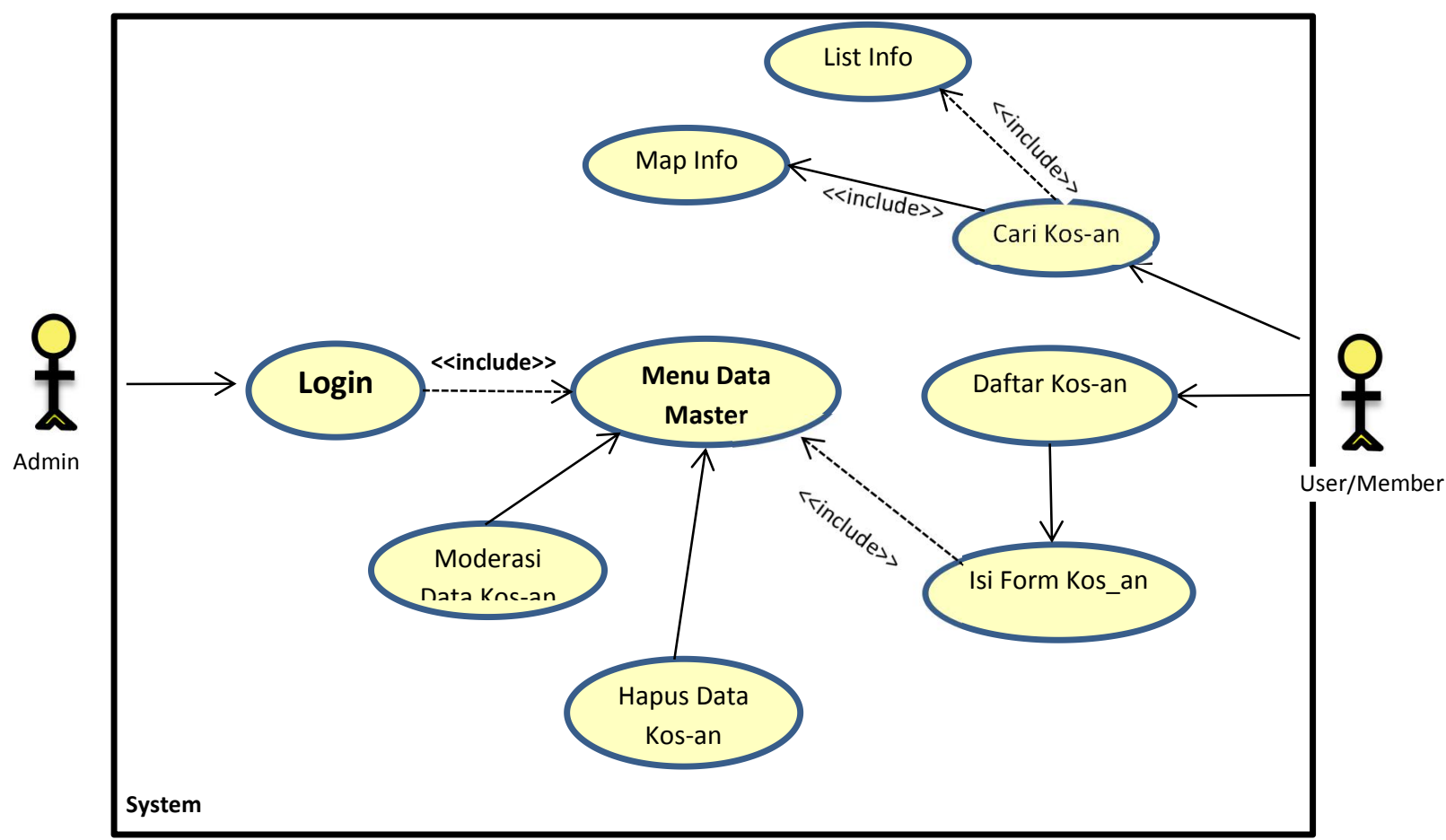

Gambar 1. Use Case

1. Hak akses administrator, memberikan keleluasaan pada admin dalam mengelola dan mengontrol setiap transaksi yang terjadi secara penuh.

2. User atau member diberi hak akses dalam proses pencarian, melihat dan memilih rumah kos dan kontrakan yang diminati, dan user juga dapat mendaftar sebagai member dengan mengisi form pendaftaran yang telah disediakan melalui sistem.

\section{LOGO}

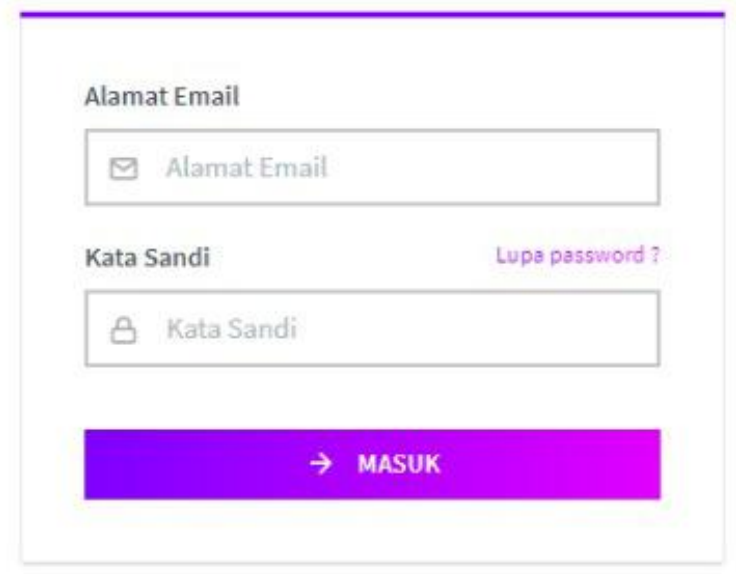

Belum punya akun ? Daftar sekarang

Gambar 2. Form Login admin 
Form login admin digunakan untuk mengakses menu data master yang berada pada halaman administrator, sehingga setelah login dilakukan admin mampu mengelola sistem informasi yang disediakan.

\section{LOGO}

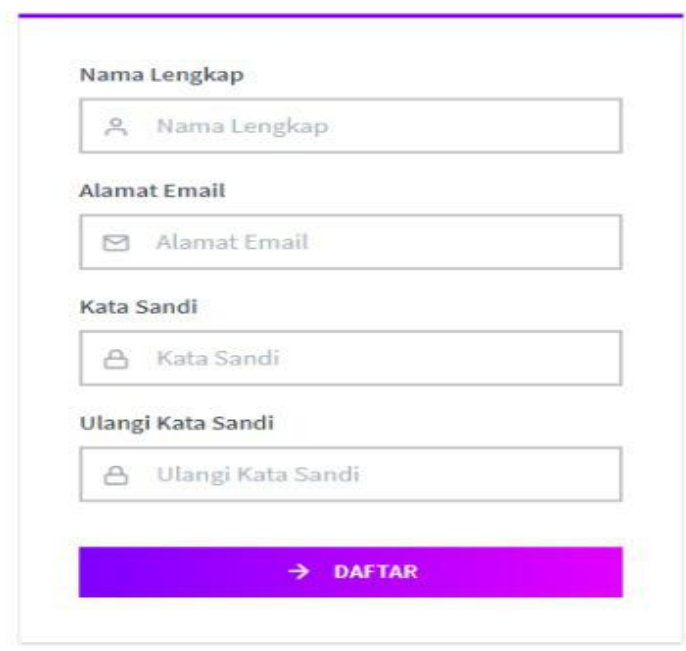

Sudah punya akun? Login sekarang

\section{Gambar 3. Halaman Registrasi User atau Member}

Pada halaman ini, user dapat melakukan registrasi pada sistem, sehingga setelah itu user mampu mendapatkan informasi terkait rumah kos dan kontrakan yang di publish.

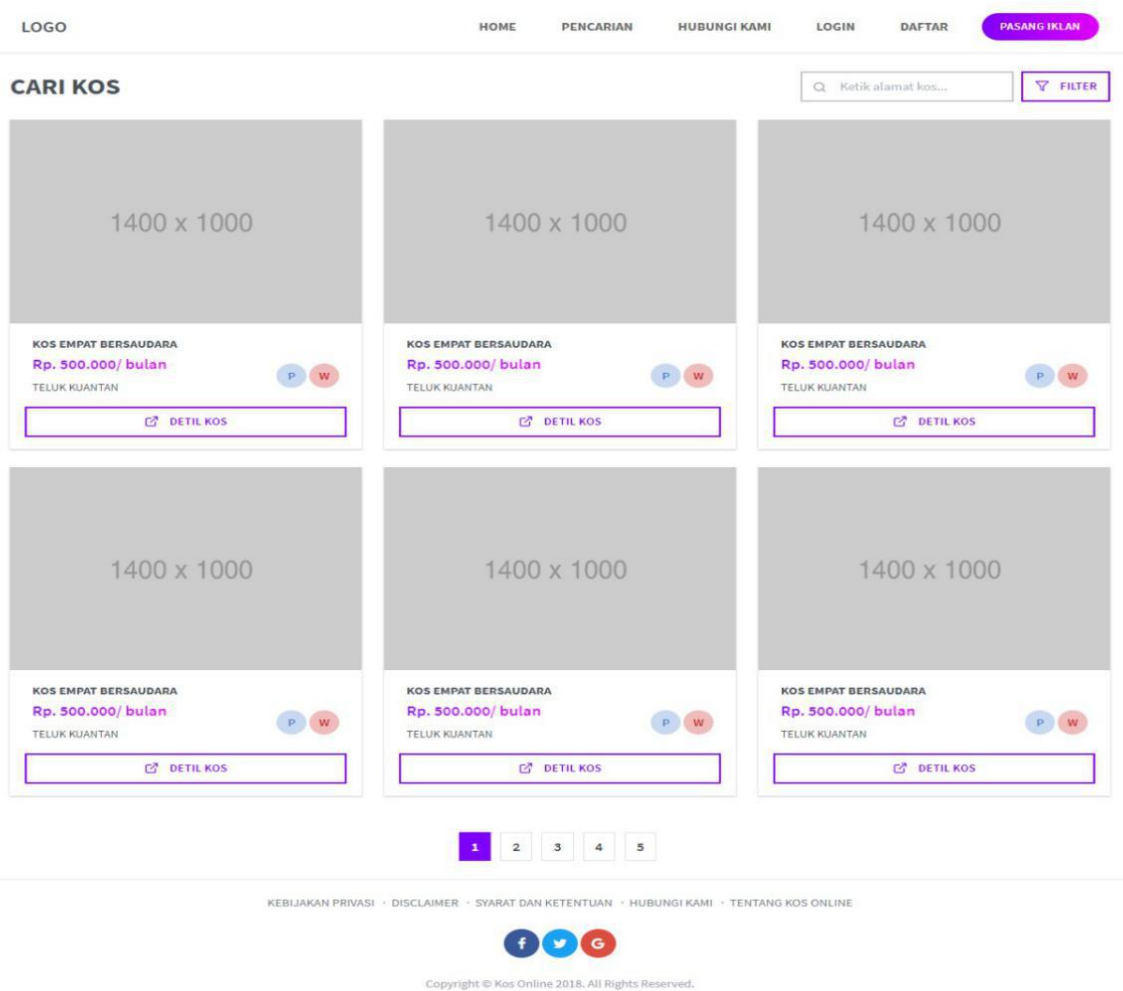

Gambar 4. Halaman Menu Utama User 
Halaman menu utama menampilkan informasi rumah kos dan kontrakan yang tersedia pada sistem informasi, dengan mengklik atau memilih salah satu, maka user dapat melihat secara detil rumah kos atau kontrakan yang disajikan.

HUBUNGI KAMI

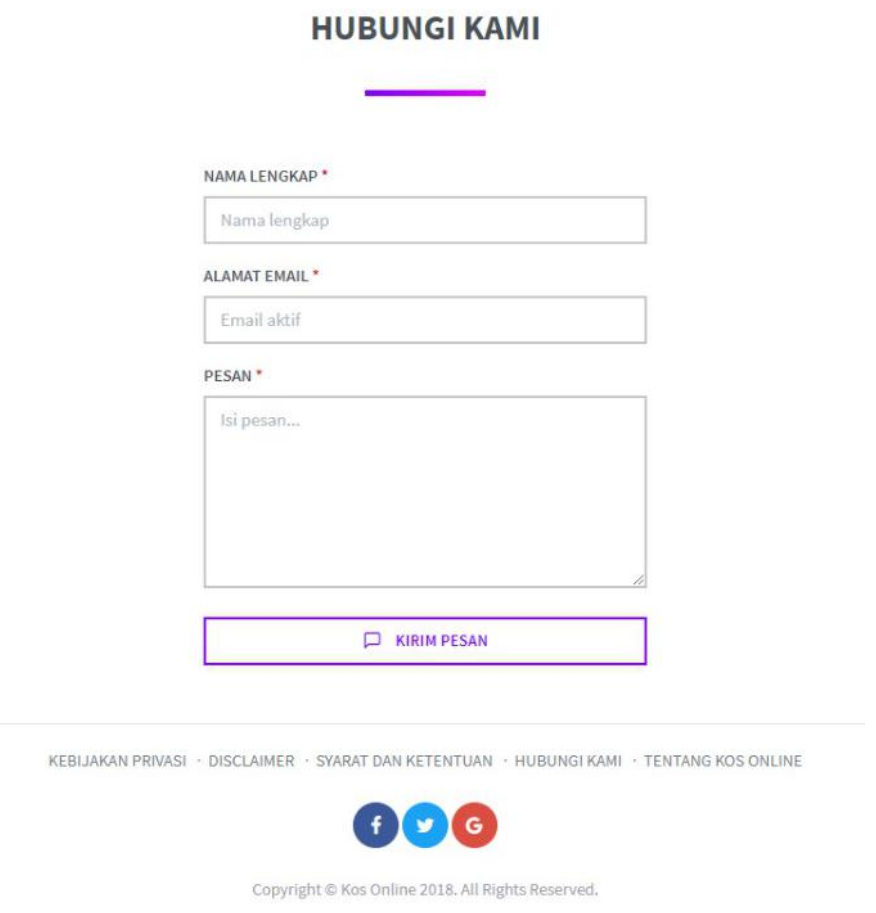

\section{Gambar 5. Halaman Kontak}

Halaman kontak berfungsi untuk berkomunikasi antara user dengan admin melalui sistem, sehingga proses interaksi dapat dilakukan, baik melalui web, facebook, twitter, google ataupun whatsapp.

\section{KESIMPULAN}

Berdasarkan penelitian yang telah dilakukan, maka dapat disimpulkan sebagai berikut :

1. Proses pencarian rumah kost dan kontrakan dapat menjadi lebih mudah, sehingga efisiensi waktu, tenaga, dan materi dapat diatasi dengan mudah.

2. Sistem Informasi rumah kost dan kontrakan memberikan kemudahan bagi user dalam pencarian rumah kost dan kontrakan sesuai kebutuhan.

3. Pemilik kost dan kontrakan mendapatkan peluang besar agar rumah kost dan kontrakannya ditemukan dan dihuni oleh pencari rumah kost dan kontrakan. 


\section{DAFTAR PUSTAKA}

Didit Gunawan, Robby Racmatullah, (2016). "Sistem Informasi Sewa Rumah Kost Dan Rumah Kontrakan Berbasis Web Di Surakarta". Jurnal Ilmiah Go Infotech, Volume 22, No. 1.

Dadi Rosadi, Feby Oktarista Andriawan, (2016). "Aplikasi Sistem Informasi Pencarian Tempat Kos Di Kota Bandung Berbasis Android”. Jurnal Computech \& Bisnis, Volume 10, No. 1, Juni 2016, 50-58, ISSN 2442-4923.

Harri Singgih Pratikto, Suraya, Edhy Sutanta, (2014). "Sistem Pencarian Dan Pemesanan Rumah Kos Menggunakan Sistem Informasi Geografi (SIG)”. Jurnal Script Vol. 1, No. 2 Januari 2014 ISSN:2338-6304.

Euis Mustika P, Sukarti, (2017). "Sistem Informasi Pencarian Tempat Kos Berbasis Geografis Di Bandar Lampung”. Jurnal Cendikia Vol. 14 No. 1, Oktober 2017. ISSN: 0216-9436 